\title{
Research on the Law of Influence of Bending Force on Strip Crown
}

\author{
Changqing Huang and Xianglei $\mathrm{Gu}^{*}$ \\ Sate Key Laboratory of High-performance Complicated Manufacturing, School of Mechanical and Electrical Engineering , Light \\ Alloy Research Institute, Central South University , Changsha 410083, China \\ ${ }^{*}$ Corresponding author
}

\begin{abstract}
Plate shape and plate convexity is an important quality index of plate d. In order to obtain the influence law about how roll bending force influence on the strip shape, This paper presents a new and more perfect mathematical model of the relationship between the bending force and strip crown and uses the simulation software MSC.MARC to verify the accuracy of the mathematical model of the relationship between the bending force and strip crown. The Simulation results show that the mathematical model of the relationship between the bending force and strip crown has the higher accuracy. The content of this thesis has a very important reference value to practical production.
\end{abstract}

Keywords-the strip shape; the bending force; the strip crown; finite element simulation; the exit thickness

\section{INTRODUCTION}

With the rapid development of modern industry, plate strip products has been widely used, as a result, the quality requirement of every industry department for plate strip has been increasingly higher and more strict. During the process from hot rolling to cold rolled, hot rolling strip shape has genetic effect to cold rolled strip shape [1], there will be a large influence on user products' lifetime and quality while plate strip shape appears strip shape defect such as large strip crown, shape wave etc., therefore, it is an urgently problem needed to solve to improve plate strip products' strip shape quality[2]. Wang Guodong academician applied the influence function to the study of bending force' influence on the strip crown[3] in the 1980s, Li Yongtang et al.[4] gave out how to set up the mathematical modeling and simulation method of hydraulic roll bending, Shi Xun[5] analyzed the influence of bending force to strip crown by using finite element theory, Zeng Chunfeng[6] studied the influence relationships between hydraulic roll bending system and strip crown from the point of the way combined with theory and experiment, the literature[7] has established the strip convexity mathematic model in theory by using elastic foundation beam method, the literature[6] completes the model in the literature[7], which takes work roll's flattening deformation affected by rolled piece into account.

In order to study the bending force's influence on strip crown and plate strip exit thickness systematically, this paper not only considers flattening factors between rolled piece and work roll, but also takes the rollers' contact flattening deformation into account, which further improves the former strip crown model.

The establishment of mathematic model between bending force and strip crown

Firstly, there are three postulated conditions before inferring mathematic model between bending force and strip crown:

The initial crown between work roll and supporting roll is zero;

Work rolls are completely contacting to supporting rolls;

Work roll neck's positive bending force $F_{w}$ is the concentrated load.

The work roll's load-deformation schematic diagram is shown in Figure 1.

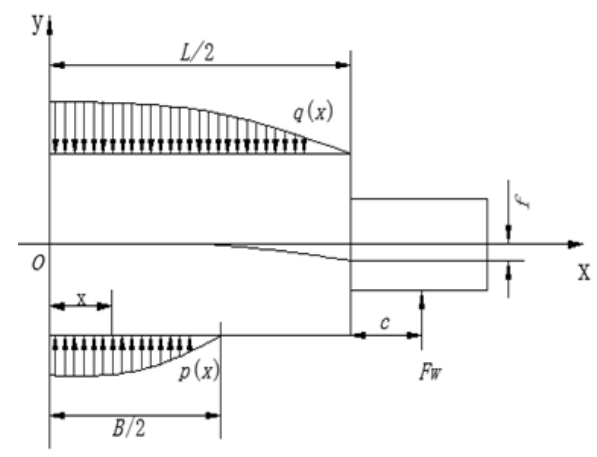

FIGURE I. THE WORK ROLL'S LOAD-DEFORMATION SCHEMATIC DIAGRAM

In Figure 1, $F_{w}$ is the positive bending force; $q(x)$ is rolls' elastic flattening load intensity; $p(x)$ is contacting load intensity between rolled piece and work roll; $L / 2$ is the halflength of work roll; $B / 2$ is the half-width of rolled piece; $f$ is the deflection of unilateral work roll.

Rolled piece's sectional form i.e. load roll gap's shape, work roll deflection under load i.e. the shape of load roll gap, according to the elements that superposition method[8] makes work roll generate deflection, we could conduct solutions 
respectively, then add these solutions together. The inference process of calculating six deflection deformations and two flattening deformations while work roll is loaded[9] is shown in the following:

Deflection $f_{1 x}$ generated by shearing force which is caused by $p(x)$ :

$$
\begin{gathered}
f_{1 x}=\frac{p(0)}{\pi G_{w} R_{w}{ }^{2}}\left(\frac{B}{2} x-\frac{1}{2} x^{2}\right)-\frac{\Delta p}{\pi G_{w} R_{w}{ }^{2}} \\
\times\left(\frac{B}{6} x-\frac{1}{3 B^{2}} x^{4}\right)
\end{gathered}
$$

Deflection $f_{2 x}$ generated by $p(x)$ when it is conducted to work roll bending moment:

$$
\begin{aligned}
& f_{2 x}=\frac{64 p(0)}{\pi E_{w} D_{w}{ }^{2}}\left(\frac{B^{3}}{16} x+\frac{3 B^{2}}{16} x^{2}+\frac{B}{4} x^{3}-\frac{1}{8} x^{4}\right)+ \\
& \frac{64 \Delta p}{\pi E_{w} D_{w}{ }^{4}}\left(-\frac{B^{3}}{32} x+\frac{7 B^{2}}{96} x^{2}-\frac{1}{30 B} x^{5}+\frac{1}{18 B^{2}} x^{6}\right)
\end{aligned}
$$

Deflection $f_{3 x}$ generated by shearing force which is caused by $q(x)$ :

$$
f_{3 x}=\frac{q(0)}{\pi G_{w} R_{w}{ }^{2}}\left(\frac{L}{2} x-\frac{1}{2} x^{2}\right)-\frac{\Delta q}{\pi G_{w} R_{w}{ }^{2}} \times\left(\frac{L}{6} x-\frac{1}{3 L^{2}} x^{4}\right)
$$

Deflection $f_{4 x}$ generated by $q(x)$ when it is conducted to work roll bending moment:

$$
\begin{gathered}
f_{4 x}=\frac{64 q(0)}{\pi E_{w} D_{w}{ }^{4}}\left(\frac{L^{3}}{16} x+\frac{3 L^{2}}{16} x^{2}+\frac{L}{4} x^{3}-\frac{1}{8} x^{4}\right)+ \\
\frac{64 \Delta q}{\pi E_{w} D_{w}{ }^{4}}\left(-\frac{L^{3}}{32} x+\frac{7 L^{2}}{96} x^{2}-\frac{L}{18} x^{3}-\frac{1}{30 L} x^{5}+\frac{1}{18 L^{2}} x^{6}\right)
\end{gathered}
$$

Deflection $f_{5 x}$ generated by shearing force which is caused by $F_{w}$ :

$$
f_{5 x}=\frac{F_{w}}{\pi G_{w} R_{w}^{2}} x
$$

Deflection $f_{6 x}$ generated by $F_{w}$ when it is conducted to work roll bending moment:

$$
f_{6 x}=\frac{F_{w}}{\pi E_{w} D_{w}{ }^{4}}\left[x^{3}-(L+2 c) x^{2}+\left(\frac{L+2 c}{2}\right)^{2} x\right]
$$

Flattening deformation $\Delta y_{w x}$ between rolled piece and work roll:
As described in the literature[10], the flattening deformation value is expressed in the following when work roll and rolled piece are contacting in the area of plate width

$$
\begin{gathered}
\Delta y_{w x}=\frac{P\left(1+\gamma_{w}\right)}{2 \pi G_{w}}\left\{l \ln \frac{\left(x+\frac{L}{2}\right)+\sqrt{\left(x+\frac{L}{2}\right)^{2}+\frac{l^{2}}{4}}}{\left(x-\frac{L}{2}\right)+\sqrt{\left(x-\frac{L}{2}\right)^{2}+\frac{l^{2}}{4}}}+\right. \\
\left(x+\frac{L}{2}\right) \ln \frac{\sqrt{\left(x+\frac{L}{2}\right)^{2}+\frac{l^{2}}{4}}+\frac{l}{2}}{\sqrt{\left(x+\frac{L}{2}\right)^{2}+\frac{l^{2}}{4}}-\frac{l}{2}}-\left(x-\frac{l}{2}\right) \times \ln \frac{\sqrt{\left(x-\frac{L}{2}\right)^{2}+\frac{l^{2}}{4}}+\frac{l}{2}}{\sqrt{\left(x-\frac{L}{2}\right)^{2}+\frac{l^{2}}{4}}-\frac{l}{2}}
\end{gathered}
$$

Besides, there is Equation (8) by consulting relative information[11]:

$l=\sqrt{R_{w} \Delta h+\left[\frac{8\left(1-\gamma_{w}{ }^{2}\right) F R_{w}}{\pi E_{w} B}\right]^{2}}+\frac{8\left(1-\gamma_{w}{ }^{2}\right) F R_{w}}{\pi E_{w} B}$

Flattening deformation $\Delta y_{w b x}$ between work roll and supporting roll:

$$
\Delta y_{w b x}=K_{w b} q(x)
$$

$$
K_{w b}=\left(\frac{1-\gamma_{w}{ }^{2}}{\pi E_{w}}+\frac{1-\gamma_{b}{ }^{2}}{\pi E_{b}}\right)\left[\frac{2}{3}+\ln \left(\frac{D_{w}}{b}\right)+\ln \left(\frac{D_{b}}{b}\right)\right]
$$

According to Hertz formula, there is Equation:

$$
b=\sqrt{2 q_{m}\left(\frac{1-\gamma_{w}{ }^{2}}{\pi E_{w}}+\frac{1-\gamma_{b}^{2}}{\pi E_{b}}\right) \frac{D_{w} D_{b}}{D_{w}+D_{b}}}
$$

In type $(1) \sim(11)$, where $G_{w} 、 E_{w} 、 \Delta p$ are work roll's shear modulus work roll's elasticity modulus loading intensity difference between plate middle part and side part, respectively; $E_{b} 、 R_{w} 、 D_{w}$ are supporting roll's elasticity modulus work roll's nonelastic flattening radius work roll's nonelastic flattening diameter, respectively; $D_{b}, b 、 \gamma_{w}$ are supporting roll's nonelastic flattening diameter half of contact width between rolls work roll's Poisson ratio, respectively; $q_{m}, \gamma_{b}, l$ are average unit contact stress supporting roll's Poisson ratio length of contact arc, respectively; $F 、 C 、 P$ are rolling pressure distance between work roll barrel margin to the corresponding central of bearing block contact pressure, respectively.

The center of work roll is regarded as fixed support during the whole inferring process, mathematic relationship model between bending and strip crown is shown in the following: 


$$
\begin{gathered}
f_{c}=K_{w} F_{w}+K_{0} \\
K_{w}=\frac{x}{\pi G_{w} R_{w}{ }^{2}}+\frac{1}{\pi E_{w} D_{w}{ }^{4}}\left(\frac{L^{4}}{4} x+\frac{L c}{2} x\right. \\
\left.-\frac{L}{2} x^{2}-\frac{c}{2} x^{2}+\frac{1}{3} x^{3}\right) \\
K_{0}=-f_{1 x}-f_{2 x}+f_{3 x}+f_{4 x}+\Delta y_{w x}+\Delta y_{w b x}
\end{gathered}
$$

Bring six different bending force into above-mentioned equation to calculate strip crown value, the result is shown in Table 1 , and the strip crown value is theoretical calculating value.

TABLE I. HALF BOARD CROWN THEORETICAL VALUE

\begin{tabular}{|c|c|c|}
\hline No. & $\begin{array}{c}\text { Bending force } \mathbf{F w} \\
(\mathbf{K N})\end{array}$ & $\begin{array}{c}\text { Half board crown fc } \\
(\mathbf{u m})\end{array}$ \\
\hline $\mathbf{1}$ & 0 & 10.7 \\
\hline $\mathbf{2}$ & 4 & 10.2 \\
\hline $\mathbf{3}$ & 8 & 9.0 \\
\hline $\mathbf{4}$ & 9.5 & 5.3 \\
\hline $\mathbf{5}$ & 11 & 5.2 \\
\hline $\mathbf{6}$ & 12 & 4.9 \\
\hline
\end{tabular}

\section{Finite ELEMENT EMULATION PROOF}

Because of the limit of experiment condition, we can't conduct experimental verification, this paper has conducted simulation analysis by applying finite element software MSC.MARC in order to illustrate mathematic model's correct between above-mentioned bending force and strip crown. This paper sets up finite element roll model on the basis of field work conditions and practical rolling technological parameters, and simulates relationship of different bending force and strip crown, then simulates effect law of different bending force and thickness distribution in plate strip exit. The parameters of finite element geometric model is shown in Table 2:

TABLE II. PARAMETERS OF FINITE ELEMENT MODEL

\begin{tabular}{|c|c|}
\hline Name & Size (mm) \\
\hline The length of support roll & 2100 \\
\hline The l diameter of support roll & 1500 \\
\hline The length of work roll & 2000 \\
\hline The l diameter of work roll & 750 \\
\hline Inlet thickness of plate & 6 \\
\hline Inlet width of plate & 1600 \\
\hline
\end{tabular}

In order to verify the convergence of finite model, this paper keeps other rolling conditions unchanged, when bending force is 0 , we adopt 6 different cell sizes to conduct mesh generation, then solve respectively, solving results are shown in Figure 3.
TABLE III. UNIT SIZE AND BASIC STRIP CROWN VALUE

\begin{tabular}{|c|c|}
\hline Unit size (mm) & Basic strip crown value (um) \\
\hline 15 & 9.8 \\
\hline 13 & 9.7 \\
\hline 10 & 10.5 \\
\hline 9 & 10.2 \\
\hline 8 & 10.2 \\
\hline 7 & 10.2 \\
\hline
\end{tabular}

From the states in Table 3, we can know that fundamental plate crown is corresponding to computed results when cell sizes are $9 \mathrm{~mm}, 8 \mathrm{~mm}$ and $7 \mathrm{~mm}$, therefore, finite element model is converged.

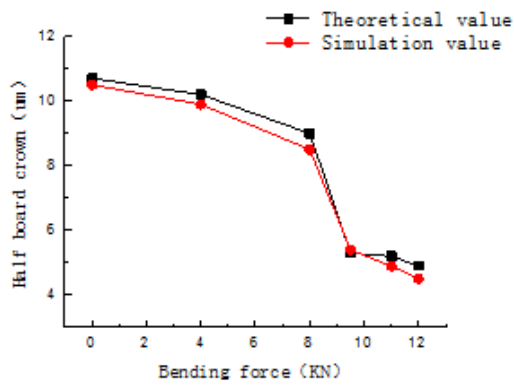

FIGURE II. THE COMPARISON OF THEORETICAL CALCULATION AND SIMULATION RESULTS

The contrast of finite element simulation results and theoretical calculation results are shown in Figure 2. The theoretical calculating results of strip crown are basically consistent to simulating calculating results, the difference is very small, thus, we can say that the theoretical calculating model's precision of strip crown is correspond to practical situation. In Figure 2, we can know that the change of strip crown is gentle when width of panel is $1600 \mathrm{~mm}$ and bending force is between $9 \mathrm{KN}$ to $11 \mathrm{KN}$, the adjustable range of bending force should contain in $9-11 \mathrm{KN}$ in this situation, and the adjustable effect of bending force to strip crown is better in this range.

There are many simulating states in this paper, the influence curves of four kinds of bending force to exit thickness are shown in Figure 3, there is obvious thickness variation and edge thinning phenomenon at about $50 \mathrm{~mm}$ from edge when there is no bending force, edge thinning phenomenon is slightly relief when the bending force is $6 \mathrm{KN}$, and when bending force reaches to $10 \mathrm{KN}$, section thickness variation trends to accord outside edge thinning zone, shape is preferable, exit thickness of rolled piece is relatively homogeneous, the thickness of edge thinning zone increases because the bending force is too large and the work roll is bending seriously when bending force is $12 \mathrm{KN}$. In the condition of rolling parameters in this paper, the best bending force is about $10 \mathrm{KN}$ by analysis, the result is within range of theoretical calculation and simulation calculating results, so this is correspond to actual situation. 


\section{CONCLUSION}

We set up a more complete mathematical model which is about the relationship of bending force and strip crown, and find out influencing theoretical calculation results of different bending force to strip crown, at the same time, we have proved the theoretical precise of bending force's influence to strip crown by the approach of finite element simulation.

The finite element model is established according to actual rolling technological parameters, we find out the influencing law of bending force to plate strip exit thickness. From the influence law of bending force to plate strip exit thickness, we can know that there is an applicable scope about bending force's control to strip shape by adjusting strip shape quality using bending roller system.

\section{ACKNOWLEDGMENT}

This study is supported by the project of National Natural Science Foundational of China : No. 51275533

\section{REFERENCES}

[1] JIANG, Z, Y, TIEU, A, K, ZHANG, X, M. Finite element modelling of mixed film lubrication in cold strip rolling[J]. Journal of Materials Processing Technology, 2004, 151(1-3): 242-247

[2] LIU Gan , YUAN Yan , ZHANG Taishan. Research of Profile and Flat Control(PFC) Model of Hot Rolled Strip [J]. Computing Technology and Automation, 2006, 25(2): 38-41.

[3] GinzburgV.B.. High-Quality Steel Rolling [M]. Beijing: Metallurgical Industry Press, 2000.

[4] LI Yongtang, LEI Bufang, GAO Yuzhuo. The modeling and simulation of hydraulic system [M]. Beijing: Metallurgical Industry Press, 2003.2.

[5] MA Chao, ZHANG Guoqiang, ZHAO Dehua, HE Tianqing, SHANG Rong. Simulation Study on effect of Bending Roller on Strip Shape [J]. ANGANG TECHNOLOGY, 2009, (5): 36-40

[6] ZENG Chunfeng. The Experimental Study Ofhydraulic Bending Rollsystem,s Effect on Platecrows [D]. Yanshan University, 2011.5.

[7] SHI Xiaoyu. Analysis\&Modeling of Profile Control for Hydraulie Bending Roll [D]. Chongqing University, 2004.

[8] LIU Hongwen. Mechanics of Materials [M]. Higher Education Press, 2004.

[9] ZHANG Zhiqiang. Strip's modeling and analysis of four-roller cold rolling mill [D].Taiyuan University of Science\&Technology, 2012.7.

[10] P, D, Sponer, and, G, F, Bryant. Analysis of Shape and Discussion of Problems of Scheduling Setup and Shape Control.[C]. UK: Proceedings of the Metals Society Conference on Shape Control, 1976.

[11] V1adimir, B, Ginsburg. Steel-Rolling Technology. Theory and practice [C]. New York: Marcel Decker. Inc, 1989: 730-795. 